\title{
Prevalence of Coronary Artery Disease Risk Factors among Male Fire-Fighters in Cape Town, South Africa
}

\author{
Ghaleelullah Achmat ${ }^{\dagger}$ \\ Rucia V November ${ }^{\dagger}$ \\ Lloyd L Leach ${ }^{*}$
}

Department of Sport, Recreation and Exercise Science, University of the Western Cape, Cape Town, Western Cape, South Africa

${ }^{\dagger}$ All authors contributed equally to this work

\begin{abstract}
Background: Cardiovascular disease is a major cause of morbidity and on-duty mortality among fire-fighters. This study investigated the prevalence of coronary artery disease (CAD) risk factors among firefighters in Cape Town, South Africa.

Methods: A quantitative, cross-sectional and correlational study design was used. A convenient sample of 219 male fire-fighters with mean age $37.85 \pm 9.80$ years was recruited. Eight major CAD risk factors were assessed using standard techniques. SPSS (ver. 23) was used with the Pearson correlation and Kruskall-Wallis $\mathrm{H}$ test with the MannWhitney test post hoc and a Bonferroni correction. The significance level set at $\mathrm{p}<0.05$.
\end{abstract}

Results: Most fire-fighters (65.29\%) were stratified as moderate risk for CAD, with $21.00 \%$ as low risk, and $14.15 \%$ as high risk. A sedentary lifestyle was the most prevalent CAD risk factor (51.14\%), followed by obesity (45.90\%). and cigarette smoking (38.30\%). Statistically significant correlations were found between waist circumference and body mass index (BMI) $(\mathrm{r}=0.711 ; \mathrm{p}<0.01)$, hip circumference and BMI $(\mathrm{r}=0.673 ; \mathrm{p}<0.01)$, waist circumference and waist-hip ratio (WHR) $(\mathrm{r}=0.665 ; \mathrm{p}<0.01)$, and body mass and BMI $(\mathrm{r}=0.512 ; \mathrm{p}<0.01)$.

Conclusion: The majority of fire-fighters were stratified as moderate risk for $\mathrm{CAD}$, and presented with multiple modifiable CAD risk factors with the most prevalent being cigarette smoking, obesity and sedentariness. Significant correlations were reported between body mass and BMI, waist circumference and BMI, and hip circumference and $\mathrm{BMI}$, as well as between waist circumference and waist-hip ratio.

Keywords: Coronary Artery Disease, Fire-Fighters, Obesity.

\section{Introduction}

Fire-fighters need good cardiorespiratory health and fitness to be able to respond to the job's demanding emergency situations [1]. Globally, it is understood that fire-fighting is a physically challenging occupation [2]. Studies have shown that coronary artery disease (CAD) is more prevalent among fire-fighters than any other occupation in the United States [3]. Approximately 50 percent of fire-fighter lineof-duty-deaths (LODDs) occur as a result of heart attacks $[3,4]$. These

\section{Article Information}

Article Type: Research Article

Article Number: JHSD 128

Received Date: 29 September, 2020

Accepted Date: 05 February, 2021

Published Date: 12 February, 2021

"Corresponding author: Lloyd L Leach, Department of Sport, Recreation and Exercise Science, University of the Western Cape, Western Cape Private Bag X17, Bellville, Cape Town, 7530, South Africa. Tel: +27-21-9592653; Email: 1leach@uwc.ac.za

Citation: Achmat G, November RV, Leach LL (2021) Prevalence of Coronary Artery Disease Risk Factors among Male Fire-Fighters in Cape Town, South Africa. J Health Sci Dev Vol: 4, Issu: 1 (01-07).

Copyright: (C) 2021 Leach LL et al. This is an open-access article distributed under the terms of the Creative Commons Attribution License, which permits unrestricted use, distribution, and reproduction in any medium, provided the original author and source are credited. 
cardiovascular events do not only happen at random, but mostly occur during very physically demanding situations, such as fire suppression [4].

Furthermore, the majority of fire-fighters who experienced these events possess one or more of the following risk factors for CAD, namely, obesity, prediabetes, dyslipidemia, high blood pressure (hypertension), cigarette smoking, and/or a sedentary lifestyle. The risk of heart attacks among fire-fighters is dependent on many factors, including factors such as a low level of physical activity, and chronic exposure to smoke. In addition, the high temperatures present during fire suppression significantly increase physiological strain and the potential to over exert the cardiovascular system [4].

Many countries in Africa bear a heavy burden from cardiovascular disease, more especially in sub-Saharan Africa [5]. In South Africa, the prevalence of cardiovascular disease has been aggravated by an increased burden of cardiovascular risk factors, such as cigarette smoking, hypertension, dyslipidemia, diabetes and sedentary lifestyles [6]. The majority of individuals affected are young and at their most productive age, and constitute the largest sector of the workforce, fire-fighters included [6].

Many of the fire-fighters, who died on-duty, did not have an up-to-date medical evaluation [2]. Hypertension, prior occlusive disease, and cigarette smoking presented as significant risk factors for on-duty-death [2]. Furthermore, some of the firefighters who were older than 45 years had up to six times the risk of cardiovascular disease [7]. Due to the scarcity of research on CAD risk factors among firefighters, especially in Africa, the purpose of this study was to determine the prevalence of CAD risk factors among firefighters in the Western Cape Province, South Africa.

\section{Methods}

\section{Research design}

A quantitative cross-sectional and descriptive design was used in this study.

\section{Recruitment of participants}

A convenient sample of 219 male career fire-fighters aged 18-65 years from the Western Cape Province, South Africa, gave their written informed consent to participate in the study.

Participants were excluded if they were administrative staff and volunteer fire-fighters (i.e., fire-fighters contracted for the peak fire season only).

\section{Data collection}

Each fire-fighter completed a researcher-generated, self-administered CAD risk factor questionnaire to obtain sociodemographic information and CAD disease-history. Risk stratification was determined according to the guidelines of the American College of Sports Medicine (ACSM) [8].

Physical measurements included stature and body mass using a combination stadiometer and beam balance scale
(Seca model 700, Gmbh \& Co., Germany). Hip and waist circumferences were measured using a non-distensible metal tape measure (Sanny Medical,rk HK). All physical measurements were done according to the guidelines of the International Society for the Advancement of Kinanthropometry (ISAK) [9]. Blood pressure was measured with a pressure cuff of appropriate size $(12 \mathrm{~cm} \times 35 \mathrm{~cm})$ using a standard mercury sphygmomanometer (Goodpro International Co., Limited, China) and an acoustic Sprague Rappaport stethoscope (Medical Supplies and Equipment Company, Houston, Texas, USA). Total cholesterol was measured with an Accutrend Plus meter (Roche Diagnostics, 04235643059, GmbH, Germany, and fasting blood sugar with an AccuCheck meter (Roche Diagnostics, 95346754160, $\mathrm{GmbH}$, Germany) using a micro-capillary blood sample from a finger-prick. The researchers calibrated all research instruments.

\section{Data analysis}

The Statistical Package for the Social Sciences (SPSS), version 23 (IBM, New York, USA) was used for data analysis. Descriptive statistics (mean and standard deviation) and inferential statistics (Pearson product-moment correlation coefficient, and the Kruskal Wallis $\mathrm{H}$ test was applied between groups with the Mann-Whitney test post hoc and a Bonferroni correction was applied to the post hoc analysis to minimise type I error, so that all effects are reported at a 0.0167 level of significance [10]. A p $<0.05$ indicated statistical significance.

\section{Ethical considerations}

The Senate Biomedical Research and Ethics Committee (BMREC) of the University of the Western Cape granted ethical clearance to conduct the study (Ethics clearance number: 14/10/52). Permission was also granted by the Chief Fire Officer of the City of Cape Town Fire and Rescue Service, as well as the Research Office of the City of Cape Town. An information letter was issued to all fire-fighters, and consent to participate voluntarily in the study was obtained in writing from each participant.

\section{Results and Discussion}

The results of the physical measurements and CAD risk factors are presented according to different weight categories in table 1 as mean $( \pm S D)$. Body mass was significantly different between the three groups $[\mathrm{H}(2)=55.705, \mathrm{p}=0.000]$. Post hoc analysis displayed significant differences between normal weight and obese groups ( $U=1597, r=-0.53)$, and overweight and obese groups ( $U=908, r=-0.38)$.

Body mass index (BMI) differed significantly between groups $[\mathrm{H}(2)=187.28, \mathrm{p}=0.00]$. Post-hoc analysis displayed significant differences between normal and overweight groups $(\mathrm{U}=0.00, \mathrm{r}=-0.79)$, normal and obese groups $(\mathrm{U}=0.00$, $r=-0.87)$, and overweight and obese groups $(U=0.00$, $\mathrm{r}=-0.79$ ).

Waist circumference was significantly different between groups $[\mathrm{H}(2)=89.870, \mathrm{p}=0.000]$. Post hoc analysis showed significant differences between normal weight and 


\begin{tabular}{|c|c|c|c|c|c|}
\hline Variables & $\begin{array}{c}\text { Total } \\
(n=219)\end{array}$ & $\begin{array}{l}\text { Normal Weight } \\
\qquad(\mathrm{n}=\mathbf{8 8})\end{array}$ & $\begin{array}{l}\text { Overweight } \\
\qquad(\mathrm{n}=38)\end{array}$ & $\begin{array}{l}\text { Obese } \\
(n=93)\end{array}$ & p-value \\
\hline Age (y) & $37.85 \pm 9.80$ & $38.46 \pm 9.80$ & $38.71 \pm 10.40$ & $36.93 \pm 9.60$ & 0.53 \\
\hline Stature $(\mathrm{m})$ & $1.71 \pm 0.10$ & $1.70 \pm 0.09$ & $1.72 \pm 0.08$ & $1.72 \pm 0.11$ & 0.39 \\
\hline Body mass (kg) & $77.51 \pm 13.89$ & $70.34 \pm 10.52$ & $74.26 \pm 9.06$ & $85.62 \pm 14.13$ & $0.00 *$ \\
\hline Body mass index $\left(\mathrm{kg} \cdot \mathrm{m}^{-2}\right)$ & $27.38 \pm 5.09$ & $22.06 \pm 1.83$ & $27.55 \pm 1.27$ & $32.34 \pm 2.38$ & $0.00 *$ \\
\hline Waist circumference $(\mathrm{cm})$ & $87.00 \pm 11.86$ & $78.90 \pm 7.97$ & $86.26 \pm 7.76$ & $94.98 \pm 11.03$ & $0.00 *$ \\
\hline Hip circumference $(\mathrm{cm})$ & $98.82 \pm 10.49$ & $92.32 \pm 6.38$ & $97.50 \pm 6.38$ & $105.51 \pm 10.93$ & $0.00 *$ \\
\hline Waist-hip ratio & $0.88 \pm 0.75$ & $0.85 \pm 0.68$ & $0.88 \pm 0.60$ & $0.90 \pm 0.80$ & $0.00 *$ \\
\hline Systolic blood pressure (mm Hg) & $121.05 \pm 17.35$ & $115.86 \pm 17.63$ & $116.58 \pm 16.85$ & $127.80 \pm 15.01$ & $0.00 *$ \\
\hline Diastolic blood pressure (mm Hg) & $79.19 \pm 9.82$ & $76.47 \pm 9.65$ & $76.97 \pm 10.17$ & $82.68 \pm 8.75$ & $0.00^{*}$ \\
\hline Total cholesterol $\left(\mathrm{mmol} \mathrm{L}^{-1}\right)$ & $5.27 \pm 0.93$ & $5.07 \pm 1.01$ & $5.42 \pm 0.90$ & $5.39 \pm 0.85$ & 0.23 \\
\hline Fasting blood glucose $\left(\mathrm{mmol} \mathrm{L}^{-1}\right)$ & $6.77 \pm 2.19$ & $5.75 \pm 2.24$ & $5.96 \pm 0.96$ & $6.65 \pm 2.42$ & $0.01 *$ \\
\hline
\end{tabular}

Table 1: Physical and CAD risk factor results of fire-fighters based on three weight categories (normal weight, overweight and obese).

overweight groups $(\mathrm{U}=850.5, \mathrm{r}=-0.39)$, normal weight and obese groups $(\mathrm{U}=882.5, \mathrm{r}=-0.68)$, and overweight and obese groups $(\mathrm{U}=933, \mathrm{r}=-037)$.

Hip circumference was significantly different between groups $[\mathrm{H}(2)=93.639, \mathrm{p}=0.000]$. Post hoc analysis displayed significant differences between normal weight and overweight groups ( $U=933, r=-0.35)$, normal weight and obese groups ( $U=808, r=-0.69)$ and overweight and obese group $(\mathrm{U}=844, \mathrm{r}=-0.41)$.

Waist-hip ratio was significant different between groups $[\mathrm{H}(2)=17.530, \mathrm{p}=0.000]$. Post hoc analysis displayed significant differences between normal weight and overweight groups ( $U=1210, r=-0.22)$, and normal weight and obese groups $(\mathrm{U}=2679, \mathrm{r}=-0.29)$.

Systolic blood pressure was significantly different between groups $[\mathrm{H}(2)=25.159, \mathrm{p}=0.000]$. Post-hoc analysis showed significant differences between normal weight and obese groups $(\mathrm{U}=2435, \mathrm{r}=-0.35)$, and overweight and obese group ( $\mathrm{U}=1123.5, \mathrm{r}=-0.29)$.

Diastolic blood pressure was significantly different between groups $[\mathrm{H}(2)=21.484, \mathrm{p}=0.000]$. Post hoc analysis displayed significant differences between normal weight and obese group $(\mathrm{U}=2513.5, \mathrm{r}=-0.33$.

Fasting blood glucose (prediabetes) was significantly different between groups $[\mathrm{H}(2)=14.136, \mathrm{p}=0.001]$. Post hoc analysis displayed significant differences between normal weight and overweight groups ( $U=1211.5, r=-0.26)$, and normal weight and obese group ( $U=3160, r=-0.26)$.

Waist circumference (WC) had a significant relationship with BMI $(\mathrm{r}=0.711, \mathrm{p}<0.01)$, waist-hip ratio $(\mathrm{r}=0.665$, $\mathrm{p}<0.01)$, systolic blood pressure (SBP) $(\mathrm{r}=0.414, \mathrm{p}<0.01)$, diastolic blood pressure (DBP) $(r=0.396, p<0.01)$, and body mass (BM) $(\mathrm{r}=0.389, \mathrm{p}<0.01)$. Waist-hip ratio (WHR) had a significant relationship with hip circumference (HC) $(\mathrm{r}=0.665, \mathrm{p}<0.01), \mathrm{SBP}(\mathrm{r}=0.414, \mathrm{p}<0.01)$, and DBP $(\mathrm{r}=0.377$, $\mathrm{p}<0.01)$. BMI had a statistically significant relationship with $\mathrm{HC}(\mathrm{r}=0.673, \mathrm{p}<0.01), \mathrm{BM}(\mathrm{r}=0.512, \mathrm{p}<0.01)$, SBP $(\mathrm{r}=0.330$, $\mathrm{p}<0.01)$, DBP $(\mathrm{r}=0.313, \mathrm{p}<0.01)$, and WHR $(\mathrm{r}=0.313, \mathrm{p}<0.01)$. Body mass had a significant correlation with $\mathrm{HC}(\mathrm{r}=0.385$, $\mathrm{p}<0.01$ ).

\section{Prediabetes}

Fig. 1 showed that $17.27 \%$ of fire-fighters presented with prediabetes. Prediabetes and obesity affected work performance of fire-fighters work making it difficult to climb ladders, especially when loaded with equipment [11]. Among 5065 fire-fighters screened for fasting glucose, 5.9\% were prediabetic and $2.7 \%$ diabetic [12]. In a cohort study of 957 career fire-fighters, approximately 26\% displayed high blood glucose levels [13]. Similarly, in 2010, among 216 fire-fighters medically screened, $32.9 \%$ were prediabetic and $14.8 \%$ were diabetic [14]. Obesity coupled with physical inactivity is related to the risk of developing diabetes and CVD [12]. The prevalence of type II diabetes among firefighters is linked with a $21 \%$ risk of experiencing an on-duty CAD event [4].

\section{Age}

Age is associated with increased risk of CAD in men aged 45 years and older (ACSM, 2014, p. 28). In figure 1, 20.51\% of fire-fighters were above the age of 45 years that placed them at moderate risk for CAD. Furthermore, physical activity tends to decrease with age and is less prevalent amongst those with chronic disease [11].

\section{Hypertension}

Hypertension is common in the South African population [6]. Hypertension was found in $27.30 \%$ of fire-fighters, and 9.41\% were pre-hypertensive (Figure 1). In the present study, blood pressure correlated significantly with body composition, i.e., WC, WHR and BMI, which together exponentially increased the risk of CAD [1,11]. For every $20 \mathrm{~mm} \mathrm{Hg}$ increase in systolic blood pressure or $10 \mathrm{~mm}$ $\mathrm{Hg}$ increase in diastolic blood pressure, the risk of CVD increases twofold [15]. Alarms, sirens, vehicle engines, and mechanized rescue equipment typically produce average noise exposures in the 63 to 85 decibel (dBA) range that increase blood pressure [3]. Siren noises elevate systolic blood pressure by 5.9 to $11.8 \mathrm{~mm} \mathrm{Hg}$ [3].

Hypertension is an independent predictor of adverse outcomes, such as injury on duty, termination of duty, resignation, premature retirement and cardiovascular events, including on-duty death [11]. Chronically 


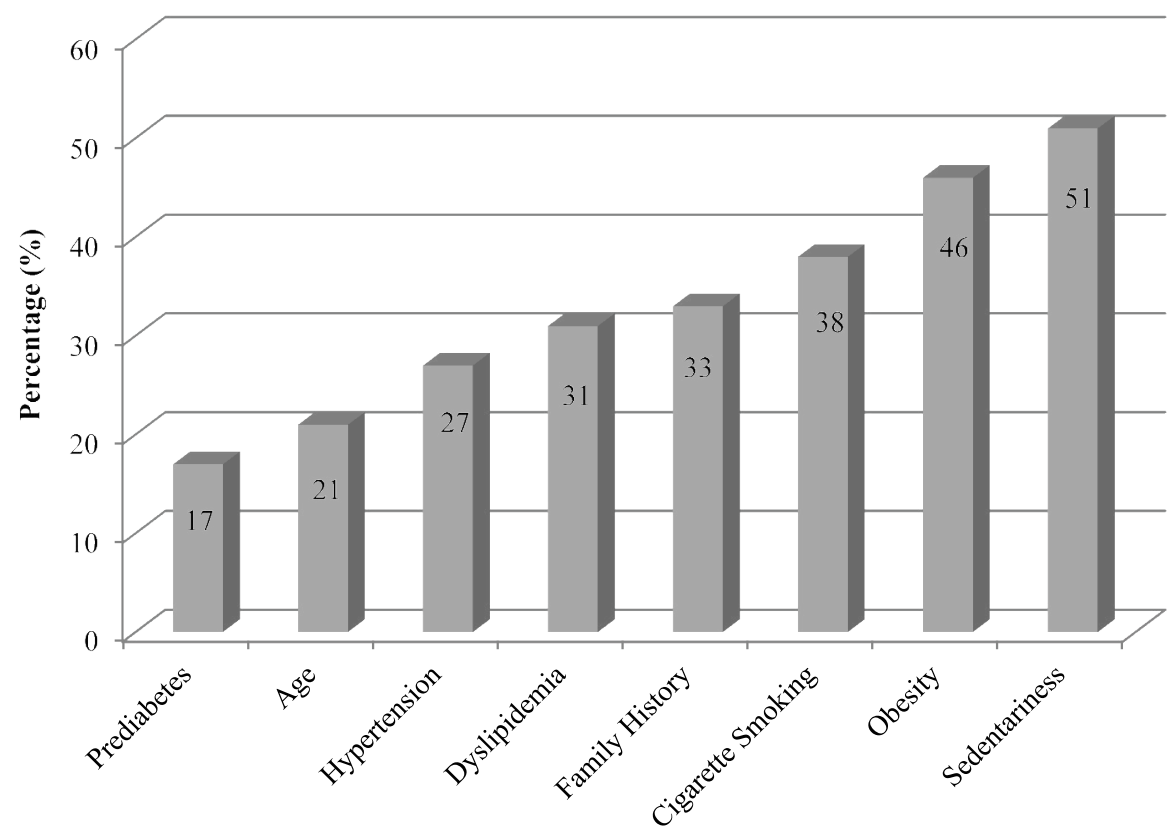

Figure 1: Prevalence of CAD risk factors among fire-fighters.

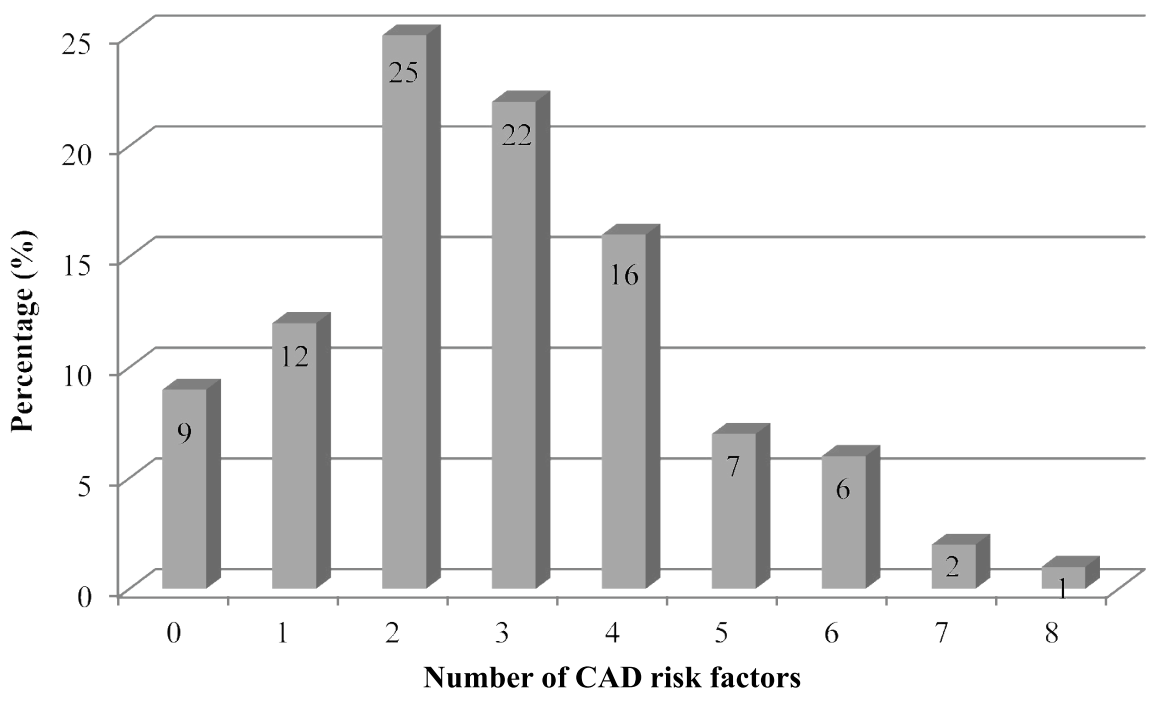

Figure 2: Frequency of CAD risk factors among fire-fighters.

uncontrolled hypertension and hypertensive heart disease were responsible for nearly $8 \%$ of cardiovascular disability retirements $[11,16]$.

\section{Dyslipidemia}

Dyslipidemia was prevalent among 31\% of fire-fighters, and has been associated with excess adipose tissue, glucose intolerance, hypertension and endothelial dysfunction, all of which affect the hearts function $[1,12,15]$. In a longitudinal study from 2004-2007, 37\% of 7904 fire-fighters had dyslipidemia [14]. Like most shift workers, fire-fighters are more likely to eat fast-foods or 'quick' meals with high proportions of fat that adversely affect blood lipid profiles and accelerate the atherosclerotic process [17].

\section{A family history of heart disease}

A family history of CAD was present in $32.80 \%$ of firefighters. The risk of CAD is exponentially increased when family history is combined with poor dietary habits, physical inactivity and smoking [18]. Family history also plays a major role in the development of prediabetes and type 2 diabetes $[16,18]$. 


\section{Cigarette smoking}

Between 1987-1994, the average prevalence of cigarette smoking amongst fire-fighters was $26.9 \%$ [19]. In the present study, cigarette smoking was prevalent in $38.30 \%$ of the fire-fighters, and is associated with other significant health and safety risks [20]. Exposure of fire-fighters to carbon monoxide contributed to the increased risk of heart disease and stroke [21]. Smokers were more likely to be diagnosed with anxiety disorder, alcohol problems and found driving under the influence than non-smokers [20].

\section{Obesity}

Being obese is a national epidemic in South Africa and a major risk factor for CAD [6]. Fire-fighters experience high rates of obesity ranging from $30 \%-40 \%$, similar to that found among the general adult population. The current study showed that $45.90 \%$ of fire-fighters were obese with high waist circumference measurements that predisposed them to increased cardiovascular events $[1,3,4]$. Overweight and obese fire-fighters often presented with multiple CAD risk factors, such as prediabetes, hypertension, and hypercholesterolemia $[1,11,16,17,22]$. Fire-fighters with a high BMI were at increased risk for work-related injuries and disabilities [4].

Fire-fighters experience weight gains of approximately 0.5 to $1.6 \mathrm{~kg}$ per year throughout their career [23]. Furthermore, the risk for diabetes increased by $4.0 \%$ for every centimetre gained around the waist [24]. Abdominal obesity, a sedentary lifestyle, hormonal imbalances, insulin resistance, and a poor diet are the prime factors in the development of metabolic syndrome [21].

\section{A sedentary lifestyle}

In the present study, a sedentary lifestyle was the most prevalent CAD risk factor, occurring in $51.14 \%$ of fire- fighters. This places fire-fighters at risk, because they do not meet the minimum physical activity requirements for health benefits, i.e., participating in at least 30 minutes of moderate-intensity (40\%-60\% VंO2max) physical activity most days of the week [8].

Physical activity is very important to fire-fighters as a public service, with work demands placing significant stress on the cardiovascular system [4]. During intense work, firefighters heart rates were reported to reach between 70 and $90 \%$ of their age-predicted maximal heart rates [25]. This, coupled with the sudden change from long periods of relative inactivity to sudden high-intensity work, while wearing relatively weighted protective fireproof clothing, increases the risk of morbidity and mortality in fire-fighters [26]. High levels of physical fitness enable fire-fighters to perform their job safely or effectively [4], and mitigate the impact of other cardiac risk factors, such as obesity and diabetes [21]. The irregular bouts of prolonged vigorous and strenuous activity required in fighting fires are a precursor to acute coronary heart events, especially in fire-fighters with low fitness levels [4].

\section{Relationship between Various CAD Risk Factors}

In figure 2 , a total of $9 \%$ of fire-fighters had zero risk factors, whereas $12 \%$ had one risk factor only, and are stratified as low CAD risk. Moderate CAD risk stratification includes two or more risk factors. Fire-fighters presenting with $2,3,4,5,6,7$, and 8 risk factors were $25 \%, 22 \%$, $16 \%, 7 \%, 6 \%, 2 \%$ and $1 \%$, respectively. Most importantly, the presence of advanced atherosclerotic lesions and pathological changes are directly correlated with the number of risk factors $[3,4,13,14]$.

Understanding the major independent CAD risk factors is critical for the fire service, due to the impact of CAD on job performance and on-duty deaths $[3,4]$. Risk factors are the

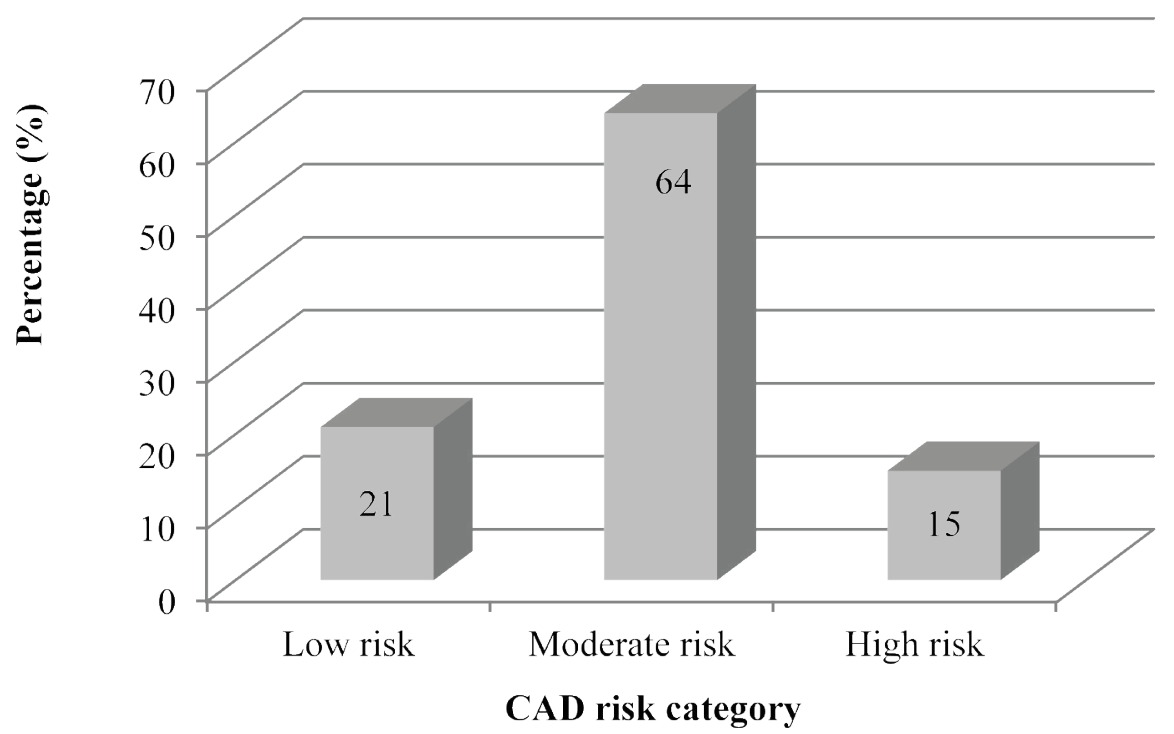

Figure 3: Coronary artery disease (CAD) risk stratification of fire-fighters. 
result of interactions between genetic and environmental factors over an extended period of time [27].

\section{CAD Risk Stratification}

Figure 3 shows that $64.4 \%$ of fire-fighters were at moderate risk for CAD, $21.0 \%$ were at low risk, and $14.6 \%$ were at high risk, particularly the older fire-fighters. In the 45 male fire-fighters aged 45 years and older, $53.33 \%$ were at high risk (i.e., diagnosed with chronic disease). An increase in age is an independent predictor of CAD in fire-fighters [4].

\section{Strengths of the Study}

There is very little research done on coronary artery disease risk factors in fire-fighters globally and, more especially, very little throughout Africa, and South Africa specifically. The study highlights the burden of coronary artery disease among firefighters in the City of Cape Town in terms of fitness for duty and public safety. It is an important public health and safety issue in the context of Africa and South Africa, and this study adds to the limited research done on this topic.

\section{Limitations of the Study}

The study did not use randomized sampling that impacted the external validity of the findings. The study did not include female fire-fighters and, therefore, has limited application with regard to female fire-fighters. The study assessed the presence of various CAD risk factors in firefighters and not the diagnosis of disease.

\section{Conclusion}

The majority of fire-fighters screened in this study were stratified as moderate risk for CAD, due to the presence of multiple modifiable (preventable) risk factors such as sedentariness, obesity and cigarette smoking. The presence of multiple modifiable CAD risk factors is cause for concern from a personal and public health perspective, especially since the risk factors are well-known, detectable, and largely preventable. Early risk assessment and disease prevention efforts are lacking in this occupational group, particularly in South Africa, and needs urgent attention [6].

\section{Acknowledgment}

The City of Cape Town Fire and Rescue Service is acknowledged for their willing participation in the study.

\section{Conflicts of Interest}

There are no conflicts of interest.

\section{References}

1. Poston WS, Haddock CK, Jahnke SA, Jitnarin N, Tuley BC, et al. (2011) The prevalence of overweight, obesity, and substandard fitness in a population-based firefighter cohort. Journal of Occupational and Environmental Medicine 53: 266-273.

2. Risavi BL, Staszko J (2016) Prevalence of risk factors for coronary artery disease in Pennsylvania (USA) fire-fighters. Prehospital and Disaster Medicine 31: 102-107.

3. Kales SN, Soteriades ES, Christophi CA, Christiani DC (2007) Emergency duties and deaths from heart disease among firefighters in the United States. New England Journal of Medicine 356: 1207-1215.
4. Soteriades ES, Smith DL, Tsismenakis AJ, Baur DM, Kales SN (2011) Cardiovascular disease in US fire-fighters: a systematic review. Cardiology in Review 19: 202-215.

5. Almahmeed W, Arnaout MS, Chettaoui R, Ibrahim M, Kurdi MI, et al. (2012) Coronary artery disease in Africa and the Middle East. Therapeutics and Clinical Risk Management 8: 65-72.

6. Mayosi BM, Lawn JE, Van Niekerk A, Bradshaw D, Karim SSA, et al. (2012) Health in South Africa: changes and challenges since 2009. Lancet 380: 2029-2043.

7. Gordon K, Kitchen E, Caine-Bish N, Staley J (2012) An assessment of cardiovascular disease risk factors and dietary intake in firefighters. Journal of Nutrition Education and Behavior 44: 48.

8. American College of Sports Medicine (2014) ACSM's guidelines for exercise testing and prescription. Lippincott, Williams and Wilkins, Philadelphia.

9. Marfell-Jones M, Olds T, Stewart A, Carter JEL (2006) International standards for anthropometric assessment. International Society for the Advanced of Kinanthropometry, Australia.

10. Field A (2009) Discovering statistics using SPSS. Sage, London.

11.0'Keefe LC (2013) Obesity, prediabetes, and perceived stress in municipal workers. Workplace Health Saf 64: 453-461.

12.Aldana S, Barlow M, Smith R, Yanowitz F, Adams T, et al. (2006) A worksite diabetes prevention program. Two-year impact on employee health. American Association of Occupational Health Nurses Journal 54: 389-395.

13. Baur DM, Leiba A, Christophi CA, Kales SN (2012) Low fitness is associated with exercise abnormalities among asymptomatic firefighters. Occupational Medicine 62: 566-569.

14.Fahy R, Leblanc P, Molis J (2014) Firefighter fatalities in the United States, 2013. National Fire Protection Association, Fire Analysis and Research Division.

15.Zhang W, Li N (2011) Prevalence, risk factors, and management of prehypertension. International Journal of Hypertension.

16. Mozaffarian D, Benjamin EJ, Go AS, Arnett DK, Blaha MJ, et al. (2016) Heart disease and stroke statistics-2016 update: a report from the American Heart Association. Circulation 133: e38-e360.

17. Jitnarin N, Poston WSC, Haddock CK, Jahnke SA, Day RS (2014) Accuracy of body mass index-defined obesity status in US firefighters. Safety and Health at Work 5: 161-164.

18. Hajar R (2017) Risk factors for coronary artery disease: Historical perspectives. Journal of the Gulf Heart Association 18: 109-114.

19. Lee DJ, LeBlanc W, Fleming LE, Gómez-Marín O, Pitman T (2004) Trends in US smoking rates in occupational groups: The National Health Interview survey 1987-1994. Journal of Occupational and Environmental Medicine 46: 538-548.

20. Haddock CK, Jitnarin N, Poston WS, Tuley B, Jahnke SA (2011) Tobacco use among fire-fighters in the central United States. American Journal of Industrial Medicine 54: 697-706.

21. International Association of Fire Fighters (2008) The fire service joint labor management wellness/fitness task force: Wellness-fitness initiative (WFI), Washington, DC: International Association of Fire Fighters, International Association of Fire Chiefs.

22. Soteriades ES, Hauser R, Kawachi I, Liarokapis D, Christiani DC, et al. (2005) Obesity and cardiovascular disease risk factors in firefighters: a prospective cohort study. Obesity 13: 1756-1763.

23. Elliot DL, Goldberg L, Kuehl KS, Moe EL, Breger RK, et al. (2007) The PHLAME (Promoting Healthy Lifestyles: Alternative Models' Effects) firefighter study: outcomes of two models of behavior change. Journal of Occupational and Environmental Medicine 49: 204-213.

24. Peer N, Steyn K, Lombard C, Lambert EV, Vythilingum B, et al. (2012) Rising diabetes prevalence among urban-dwelling black South Africans. Public Library of Science 7: e43336. 
25. Phillips M, Payne W, Lord C, Netto K, Nichols D, et al. (2012) Identification of physically demanding tasks performed during bushfire suppression by Australian rural fire-fighters. Applied Ergonomics 43: 435-441.

26. Mier CM, Gibson AL (2004) Evaluation of a treadmill test for predicting the aerobic capacity of firefighters. Occupational Medicine 54: 373-378.

27.0’Donnell CJ, Elousa R (2008) Cardiovascular risk factors - Insights from Framingham Heart Study. Revista Espanola De Cardiologia 61: 299-310.

Citation: Achmat G, November RV, Leach LL (2021) Prevalence of Coronary Artery Disease Risk Factors among Male Fire-Fighters in Cape Town, South Africa. J Health Sci Dev Vol: 4, Issu: 1 (01-07). 